\title{
Noise and Vibration in Complex Hydraulic Tubing Systems
}

\author{
Chuan-Chiang Chen \\ Mechanical Engineering Department, \\ California State Polytechnic University Pomona,
}

USA

\section{Introduction}

In hydraulic systems, pumps are the major source of noise and vibration. It generates flow ripples which interact with other hydraulic components, such as transmission lines and valves to create harmonic pressure waves, i.e., fluid-borne noise (FBN). Fig. 1 shows a typical oscillating pressure measured at the outlet of a ten-vane pump running at $1500 \mathrm{rpm}$. Fig. 2 gives the frequency spectrum for the pressure signal which contains harmonic components of the fundamental frequency, $25 \mathrm{~Hz}$, which correlates with the pump operating speed. The largest peak is at $250 \mathrm{~Hz}$, which corresponds to the shaft speed times the number of the pumping elements (10 vanes in this case). The FBN propagates along as well as interacts with the tubing and other components to result in airborne noise (ABN) and structure-borne noise (SBN, i.e., structural vibration). These noises can become excessive, and lead to damage the tubing system and other components. Therefore, to study the pressure wave propagation in the hydraulic tubing system, it is important to take the fluid-structure interaction into account to further the understanding of noise transmission mechanism.

Fluid-structure interaction can be divided into three categories: junction coupling, Poisson coupling, and Bourdon coupling. Junction coupling occurs at discontinuities, such as bends and tees, where the pressure interacts with the structure to cause structural vibration. In unsteady flow, the pressure varies along the tube. Differences in pressure exert axial and transverse forces during power transmission at bends and other locations where the diametrical geometry changes. Moreover, the pressure is related to the longitudinal stresses in the pipe because of the radial contraction or expansion via Poisson coupling (Hatfield \& Davidson, 1983). Furthermore, the cross-sectional shape of the line in a bend is not circular because of action by the bending forces. This effect, known as the Bourdon effect (Tentarelli, 1990), influences the structural modes at low frequencies.

Several approaches have been used (To \& Kaladi, 1985; Everstine 1986; Nanayakkara \& Perreia, 1986), such as the transfer matrix and finite element (FEM) methods, to model the fluid-structural coupling. In this study, the transfer matrix method (TMM) is used because of its simplicity. Even though FEM may offer better accuracy, it is more complicated and time-consuming than TMM. 


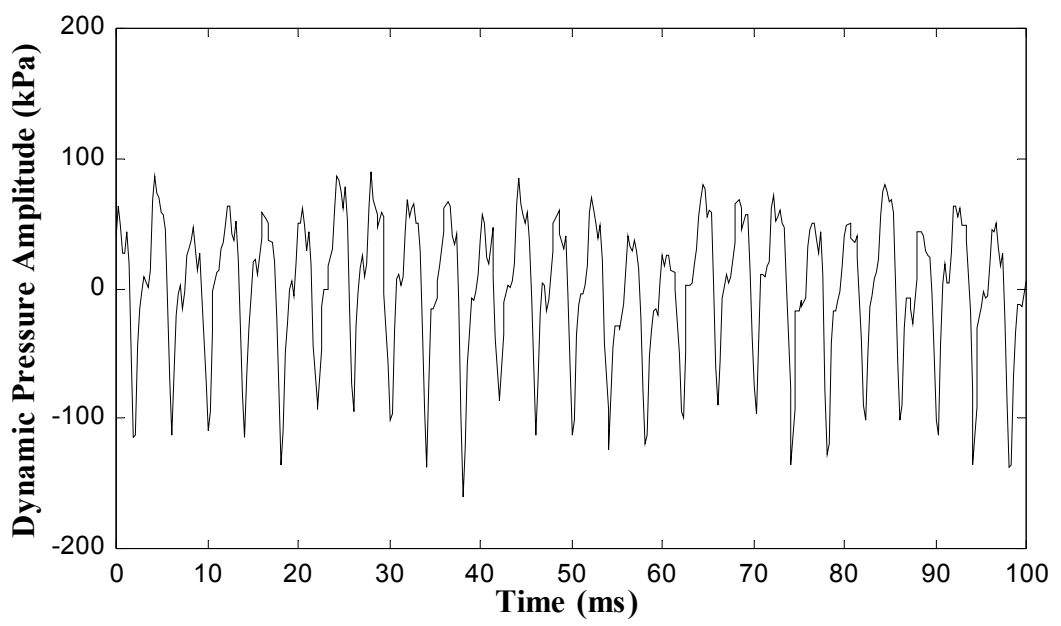

Fig. 1. Pressure waveform measured at the outlet of a ten-vane power steering pump running at $1500 \mathrm{rpm}$. The periodic waveform is generated by the rotating elements of the pumping mechanism.

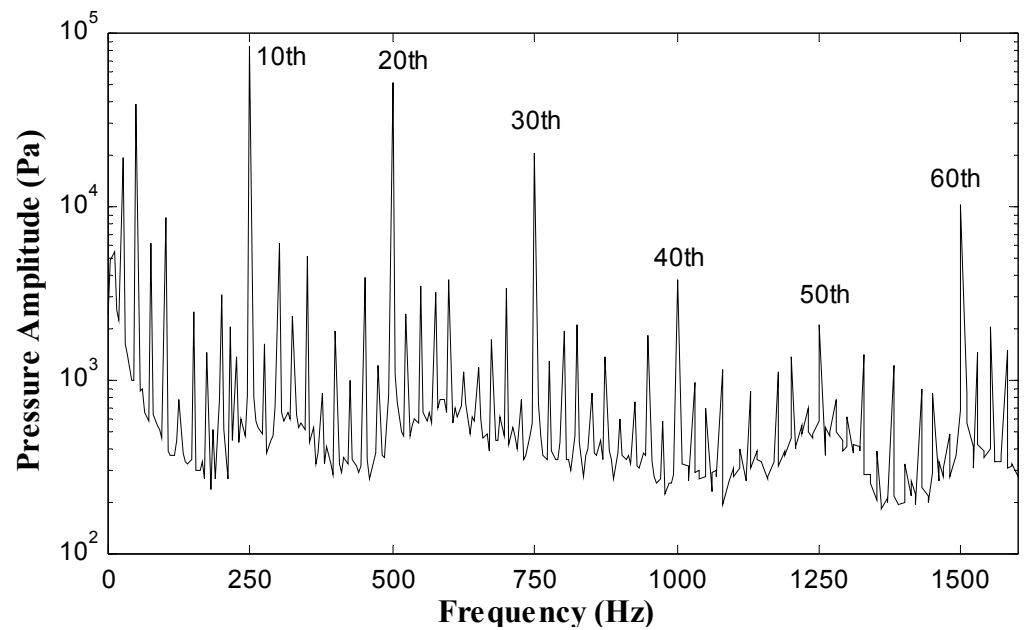

Fig. 2. Frequency spectrum of the pressure signal shown in Fig. 1 Pump speed: 1500 rpm; number of pumping elements: 10; fundamental pump rotational frequency: $25 \mathrm{~Hz}$

Davidson and Smith (1969) first studied fluid-structure interactions using the TMM and verified their model with their own experimental data. Their data were used widely by subsequent researchers (Davidson \& Samsury, 1972; Hatfield \& Davidson, 1983) to verify analytical models which did not include viscosity. Hatfield et al. (1982) applied the component synthesis method in the frequency domain. In their method, fluid-structure interaction was included in terms of junction coupling. Their simulation predictions were validated with Davidson and Smith's (1969) experimental data. Bundy et al. [9] introduced 
structural damping which was neglected by other researchers in previous experimental and theoretical investigations.

Brown and Tentarelli (1988) arranged the $14 \times 14$ transfer matrices for $n$ segments and then assembled them into a global $14(\mathrm{n}-1) \times 14(\mathrm{n}-1)$ sparse matrix. This approach was beneficial because, by solving the linear equations, the state variables at every point were obtained. Their algorithm also avoided round-off error at higher frequencies. Fluid friction was not considered in their analysis. Chen (1992), and Chen and Hastings (1992; 1994) considered both the fluid-structure interaction caused by discontinuities and the viscosity of the fluid in a distributed parameter, transfer matrix model of the transmission line in an automotive power steering system.

Most researchers verified their models with a simplified experimental system; for example, L-tube or U-tube systems. Until now, the system model has not been verified in a complex tubing system. In this book, a transfer matrix system model incorporating the acoustic characteristics of termination is developed to predict the fluidborne noise in a complex three-dimensional tubing system. The results show good agreements between simulated and experimental data.

\section{Analysis}

\subsection{Axial motion}

For a three-dimensional tubing system, fluid-structural coupling must be considered because tubing discontinuities, such as bends, cause unbalanced forces to act on both the tubing and fluid. Fig. 3 displays the coordinate system and state variables in a straight tube segment used in the following analysis.

Assuming axisymmetric, two-dimensional, laminar, viscous, compressible flow and negligible temperature variation (i.e., constant fluid viscosity), the linearized Navier-Stokes equations reduce to (Chen, 2001):

$$
\frac{\partial v_{z}}{\partial t}=-\frac{1}{\rho_{f}} \frac{\partial p}{\partial z}+v\left[\frac{\partial^{2} v_{z}}{\partial r^{2}}+\frac{1}{r} \frac{\partial v_{z}}{\partial r}\right]
$$

where $v_{z}, v_{r}$, and $p$ denote the deviation of axial velocity, radial velocity, and pressure from the steady state, respectively.

Combining the continuity equation and equation of state for a liquid, gives:

$$
\frac{1}{\beta} \frac{\partial p}{\partial t}+\frac{\partial v_{r}}{\partial r}+\frac{v_{r}}{r}+\frac{\partial v_{z}}{\partial z}=0
$$

where $\beta$ is the fluid bulk modulus.

By averaging $v_{z}$ over the cross section, applying the boundary condition at the inner radius of the tubing, $u_{f}=u_{z}$, and transforming to the Laplace domain, the following equation is obtained: 


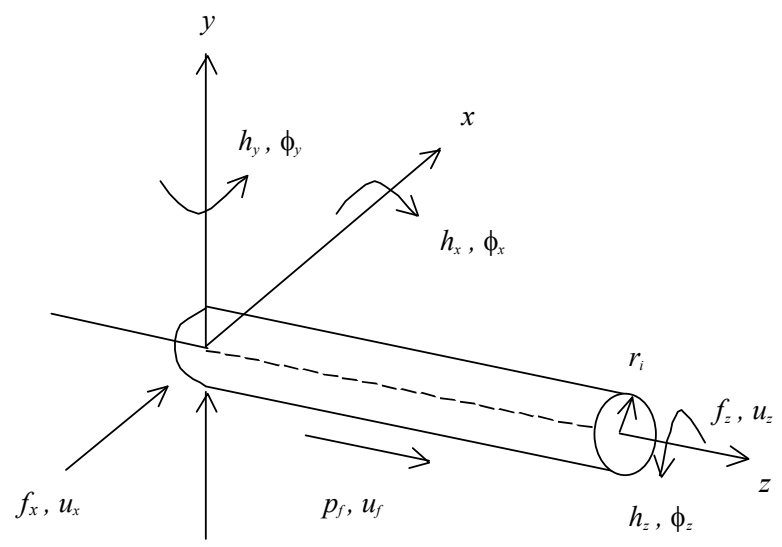

$f_{y}, u_{y}$

Fig. 3. Hydraulic line coordinate system and state variables: $u$ is translational displacement of tubing; $\phi$, angular displacement of tubing; $f$, force acting on the tubing; $h$, moment acting on the tubing; $p_{f}$, fluid pressure; $u_{f}$, fluid displacement; and subscripts $x, y$, and $z$ the axes for the Cartesian coordinates (adapted from Chen, 1992).

$$
\frac{\partial P}{\partial z}=\frac{\rho_{f} s^{2}}{\Omega(s)} U_{f}-\rho_{f} s^{2}\left[\frac{1+\Omega(s)}{\Omega(s)}\right] U_{z}
$$

where $\Omega(s)=\left[\frac{2 J_{1}\left(j r_{i} \sqrt{s / v}\right)}{j r_{i} \sqrt{s / v} J_{i}\left(j r_{i} \sqrt{s / v}\right)}-1\right], \rho_{f}$ is the fluid density, and $\mathrm{J}_{\mathrm{O}}$ and $\mathrm{J}_{1}$ are the zero- and first-order Bessel functions of the first kind, respectively, and $s$ denotes the Laplace transformation.

Applying Newton's second law to the tubing wall, yields:

$$
F_{\tau}+\frac{\partial F_{z}}{\partial z}=\rho A s^{2} U_{z}
$$

where $F_{\tau}$ is the friction force per unit length acting on the inner tubing wall, $A$ is the crosssectional area of the tubing, and $\rho$ is the density of the tubing.

Applying Newton's second law to the fluid gives:

$$
-A_{f} \frac{\partial P}{\partial z}-F_{\tau}=\rho_{f} A_{f} s^{2} U_{f}
$$

where $A_{f}$ is the cross-sectional area of the fluid.

Combining Equations (4) and (5), gives:

$$
\frac{\partial F_{z}}{\partial z}-A_{f} \frac{\partial P}{\partial z}=\rho A s^{2} U_{z}+\rho_{f} A_{f} s^{2} U_{f}
$$


Substituting Equation (3) into Equation (6), and rearranging Equation (6) yields:

$$
\frac{\partial F_{z}}{\partial z}=\left\{\rho A-\rho_{f} A_{f}\left[1+\frac{1}{\Omega(s)}\right]\right\} s^{2} U_{z}+\rho_{f} A_{f}\left[1+\frac{1}{\Omega(s)}\right] s^{2} U_{f}
$$

\subsubsection{Poisson effect}

The Poisson effect, longitudinal motion resulting in radial strain of the tubing or vice versa, was not included in previous work (Chen, 1992). The axial strain of the tubing, $\varepsilon_{z}$, in a cylindrical coordinates is written as:

$$
\varepsilon_{z}=\frac{\partial u_{z}}{\partial z}=\frac{1}{E}\left(\sigma_{z}-\mu \sigma_{r}-\mu \sigma_{\theta}\right)
$$

where $\sigma$ is the stress, $E$ and $\mu$ are the elastic modulus and Poisson's ratio for the tubing material, respectively, and subscripts $z, r$ and $\theta$ are the cylindrical coordinates.

For thick-walled tubing, the radial and tangential stresses can be represented as:

$$
\sigma_{r}+\sigma_{\theta}=\frac{2 p r_{i}^{2}}{r_{o}^{2}-r_{i}^{2}}
$$

Combining Equations (8) and (9), gives:

$$
\frac{\partial u_{z}}{\partial z}=\frac{1}{E A} f_{z}-\frac{2}{E} \frac{r_{i}^{2} \mu}{\left(r_{o}^{2}-r_{i}^{2}\right)} p
$$

For conservation of mass to hold, the axial change in volume of a fluid element results from pressure and expansion of the tubing. Radial expansion of the tubing is caused by pressure, and axial motion of the tubing results from Poisson coupling:

$$
\frac{\partial u_{f}}{\partial z}=\frac{2 \mu}{E A} f_{z}-\frac{1}{\beta_{e}} p
$$

where $\beta_{e}$ is an effective fluid bulk modulus that accounts for compliance of the tubing wall. When the Poisson effect is neglected, Equations (10) and (11) reduce to equations for longitudinal motion of a bar.

\subsubsection{Bourdon coupling}

The Bourdon effect occurs at bends where the fluid-filled tubing cross-section is ovalized. Bending of the tubing results in a change of cross-sectional area and thus fluid motion. The fluid pressure gradient in the bend produces a bending moment in the tubing, and the balancing bending moment in the tubing then displaces the fluid. For curved tubing, the Bourdon coupling is described by Reissner et al. (1952) and Tentarelli (1990):

$$
\frac{\partial u_{z}}{\partial z}=A_{11} p+A_{12} h_{y}
$$


where $\quad A_{11}=\frac{1}{R_{v}}\left(1-\frac{b^{2}}{a^{2}}\right)\left[1-\frac{2 R_{v}\left(r_{o}-r_{i}\right)}{a b \sqrt{12\left(1-v^{2}\right)}}\right] \frac{b^{2}-a^{2}}{E a\left(r_{o}-r_{i}\right)^{2}}\left[\sqrt{3\left(1-v^{2}\right)}-\frac{R_{v}\left(r_{o}-r_{i}\right)}{a b}\right]$,

$$
\frac{\partial \phi_{y}}{\partial z}=A_{21} p+A_{22} h_{y}
$$
$A_{22}=\frac{a \sqrt{12\left(1-v^{2}\right)}}{2 \pi E b^{2} R_{v}\left(r_{o}-r_{i}\right)^{2}}, \quad A_{12}=\frac{-1}{\pi R_{v} a b} \frac{b^{2}-a^{2}}{E a\left(r_{o}-r_{i}\right)^{2}}\left[\sqrt{3\left(1-v^{2}\right)}-\frac{R_{v}\left(r_{o}-r_{i}\right)}{a b}\right]$, $A_{21}=\frac{b^{2}-a^{2}}{E a\left(r_{o}-r_{i}\right)^{2}}\left[\sqrt{3\left(1-v^{2}\right)}-\frac{R_{v}\left(r_{o}-r_{i}\right)}{a b}\right], R_{v}$ is the radius of curvature of the bend, and $a$ and $b$ are the major and minor axes of the elliptical cross section, respectively.

Equations (12) and (13) reduce to the common flexural motion equations for $a=b$ (i.e., circular cross-section). When there is no fluid pressure present, $A_{22}$ can be approximated as a flexural stiffness with a correction factor to account for the ovalization effect. The effect produces a reduction in stiffness at bends in the transmission line.

Several straight short-length segments are used to model the bends and twists in the threedimensional tubing line. To account for the ovalization effect, a correction factor is used to adjust the flexural stiffness for the curved line. The correction factor $(\kappa)$ for the flexural stiffness is formulated as Vigness (1943):

$$
\kappa=\frac{1+12\left[4\left(r_{o}-r_{i}\right) R_{v} /\left(r_{o}+r_{i}\right)^{2}\right]}{10+12\left[4\left(r_{o}-r_{i}\right) R_{v} /\left(r_{o}+r_{i}\right)^{2}\right]}
$$

The product of $\kappa$ and a flexural stiffness can be shown to be a simplified form of $A_{22}$ (Reissner et al., 1956).

\subsection{Flexural and torsional motion}

Rearranging Equations (3), (7), (10) and (11), and considering the flexural motions in the $x-z$ and $y-z$ planes, and torsion about the $z$-axis in Laplace domain, four groups of linear, firstorder differential equations are obtained (Chen 2001):

$$
\frac{\partial}{\partial z}\left[\begin{array}{c}
P \\
F_{z} \\
U_{f} \\
U_{z}
\end{array}\right]=-\left[\begin{array}{cccc}
0 & 0 & \frac{-\rho_{f} s^{2}}{\Omega(s)} & \rho_{f} s^{2}\left[\frac{1+\Omega(s)}{\Omega(s)}\right] \\
0 & 0 & -\rho_{f} A_{f} s^{2}\left[\frac{1+\Omega(s)}{\Omega(s)}\right] & -s^{2}\left\{\rho A-\rho_{f} A_{f}\left[\frac{1+\Omega(s)}{\Omega(s)}\right]\right\} \\
\frac{1}{\beta_{e}} & \frac{-2 \mu}{E A} & 0 & 0 \\
\frac{2 \mu r_{i}^{2}}{E\left(r_{o}^{2}-r_{i}^{2}\right)} & \frac{-1}{E A} & 0
\end{array}\right]\left[\begin{array}{c}
P \\
F_{z} \\
U_{f} \\
U_{z}
\end{array}\right]
$$




$$
\begin{aligned}
& \frac{\partial}{\partial z}\left[\begin{array}{c}
U_{x} \\
H_{y} \\
F_{x} \\
\Phi_{y}
\end{array}\right]=-\left[\begin{array}{cccc}
0 & 0 & -1 / G A & -1 \\
0 & 0 & 1 & -\left(\rho I+\rho_{f} I_{f}\right) s^{2} \\
-\left(\rho A+\rho_{f} A_{f}\right) s^{2} & 0 & 0 & 0 \\
0 & -1 / E I & 0 & 0
\end{array}\right]\left[\begin{array}{c}
U_{x} \\
H_{y} \\
F_{x} \\
\Phi_{y}
\end{array}\right] \\
& \frac{\partial}{\partial z}\left[\begin{array}{c}
U_{y} \\
H_{x} \\
F_{y} \\
\Phi_{x}
\end{array}\right]=-\left[\begin{array}{cccc}
0 & 0 & -1 / G A & 1 \\
0 & 0 & -1 & -\left(\rho I+\rho_{f} I_{f}\right) s^{2} \\
-\left(\rho A+\rho_{f} A_{f}\right) s^{2} & 0 & 0 & 0 \\
0 & -1 / E I & 0 & 0
\end{array}\right]\left[\begin{array}{c}
U_{y} \\
H_{x} \\
F_{y} \\
\Phi_{x}
\end{array}\right] \\
& \frac{\partial}{\partial z}\left[\begin{array}{c}
H_{z} \\
\Phi_{z}
\end{array}\right]=-\left[\begin{array}{cc}
0 & -\rho J s^{2} \\
-1 / G J & 0
\end{array}\right]\left[\begin{array}{l}
H_{z} \\
\Phi_{z}
\end{array}\right]
\end{aligned}
$$

Equations (15) - (18) can be represented in the following form:

$$
\frac{\partial}{\partial z}\left[S_{k}\right]=-\left[A_{k}\right]\left[S_{k}\right] ; k=1,4
$$

where $\left[A_{k}\right]$ is coefficient matrix, $S_{1}=\left[\begin{array}{llll}P & F_{z} & U_{f} & U_{z}\end{array}\right]^{\mathrm{T}}, \quad S_{2}=\left[\begin{array}{llll}U_{x} & H_{y} & F_{x} & \Phi_{y}\end{array}\right]^{\mathrm{T}}$, $S_{3}=\left[\begin{array}{llll}U_{y} & H_{x} & F_{y} & \Phi_{x}\end{array}\right]^{\mathrm{T}}$ and $S_{4}=\left[\begin{array}{ll}H_{z} & \Phi_{z}\end{array}\right]^{\mathrm{T}}$.

Solving Equation (16) by employing boundary conditions at the inlet $(z=0)$ of each section yields:

$$
\left[S_{k}\right]_{z=L}=e^{-\left[A_{k}\right] L}\left[S_{k}\right]_{z=0}
$$

where $\left[S_{k}\right]_{z=0}$ is the substate vector at the inlet.

Relating the two end conditions for a given section $i$, yields the $14 \times 14$ field transfer $\operatorname{matrix}[T]_{i}$ :

$$
[S]_{i+1}=[T]_{i}[S]_{i}
$$

A three-dimensional tubing system can be treated as a combination of short straight lines with different orientations resulting in coupling of the fluid pressure, and forces and moments in the tubing wall. Each section of tubing is modeled by a $14 \times 14$ transfer matrix with state variable vectors. Details on the assembly of the $14 \times 14$ matrix can be found in Chen [11]. Each bend is broken into three straight-line segments. For these segments, the correction factor, $\kappa$, is used to include the Bourdon effect by replacing the flexural stiffness $E I$ with $\kappa E I$ in Equation (14).

A transformation matrix $[R]$ transfers the force and displacement from one section to another, couples structural vibration and fluid pressure waves at points of discontinuity, and transforms the coordinate system from one section to the next. Force and moment 
equilibrium, conservation of mass flow, and structural continuity are considered when deriving the transformation matrix (Chen, 1992). Finally, the relationship between one end of the system and the other is obtained by multiplying $[R]$ and $[T]$ for each line section:

$$
[S]_{n+1}=[R]_{n}[T]_{n} \cdots \cdots \cdots[R]_{1}[T]_{1}[S]_{1}
$$

\subsection{Implementation of the matrix partitioning algorithm}

The transfer matrix method solves the equations of motion step by step and determines the unknown variables (translational displacement, angular displacement, force and moment) simultaneously in the solution process. Because of the transfer matrix chain multiplication, as shown in Equation (22), numerical errors occur and build up as the multiplicative process progresses. In this study, matrix partitioning was applied to the system of equations to eliminate the long chain of matrix multiplication.

In most tubing systems, the boundary conditions at each end are defined because the tubing is attached to the pump outlet and the rotary valve inlet. Therefore, to reduce numerical error, matrix partitioning originally developed by (Clark, 1956) was used. With known boundary conditions at the ends, the state variables are re-arranged as follows:

$$
\begin{gathered}
{[S]_{1}^{*}=\left\{\begin{array}{l}
S_{1}^{a} \\
S_{1}^{b}
\end{array}\right\}} \\
{[S]_{n+1}^{*}=\left\{\begin{array}{l}
S_{n+1}^{a} \\
S_{n+1}^{b}
\end{array}\right\}}
\end{gathered}
$$

where $S_{1}{ }^{a}$ and $S_{n+1}{ }^{a}$ are the known state variables, and $S_{1}{ }^{b}$ and $S_{n+1}{ }^{b}$ are the unknown variables.

By using the matrices $[M R]_{1}$ and $[M R]_{n+1}$, the following equations are obtained:

$$
\begin{gathered}
{[S]_{1}^{*}=[M R]_{1}[S]_{1}} \\
{[S]_{n+1}^{*}=[M R]_{n+1}[S]_{n+1}} \\
{[S]_{1}=[M R]_{1}^{-1}[S]_{1}^{*}}
\end{gathered}
$$

The relationship between one end and the other for the first element is:

$$
[S]_{2}=[T R]_{21}[S]_{1}
$$

where $[T R]_{21}=[R]_{1}[T]_{1}$.

Combining Equations (27) and (28) and arranging the unknown variables on the left side, yields: 


$$
\left.\left[\begin{array}{cc}
T_{21}^{*} & -I \\
1: 14, b+1: 14 & 1: 14,1: 14
\end{array}\right] \underset{(a+14) \times 1}{\left[\begin{array}{c}
S_{1}{ }^{b} \\
S_{2}
\end{array}\right]}=-\underset{14 R \times 14)}{[T R}\right]_{21}^{*} \underset{14 \times 1}{\left[\begin{array}{c}
S_{1}{ }^{a} \\
0
\end{array}\right]}
$$

where $[T R]_{21}^{*}=[T R]_{21}[M R]_{1}^{-1}$.

Similarly, the equation of the last section of tubing can be written as:

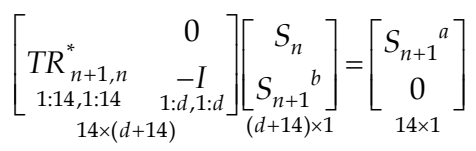

where $[T R]_{n+1, n}^{*}=[M R]_{n+1}[T R]_{n+1, n}$ and $[T R]_{n+1, n}=[R]_{n}[T]_{n}$.

By rearranging the equations for all tubing sections, the global matrix is obtained:

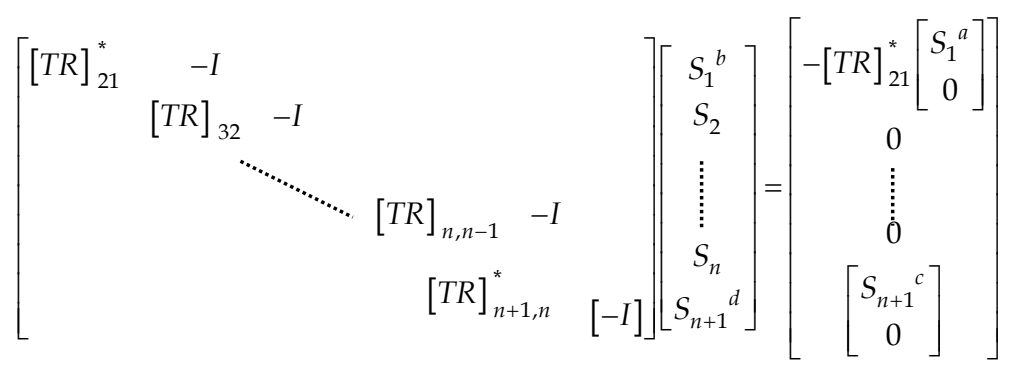

To solve for the unknown state variables in Equation (31), MATLAB ${ }^{\circledR}$ command " $\backslash$ ”, which solves the system of linear equations by Gaussian elimination, was used in the simulation.

\subsection{Acoustic impedance of hydraulic system components}

Impedance characteristics of hydraulic components have an important effect on pressure pulsations in hydraulic circuits. These pressure oscillations lead to vibrations and are a source of noise. By using plane wave propagation theory, impedances can be estimated using the two-microphone technique (ASTM E 1050-90, and ASTM C 384-108a).

Fig. 4 displays an acoustic impedance representation for the hydraulic circuit Five parameters can be used to define this system: the source impedance $\left(Z_{s}\right)$, source flow ripple $\left(Q_{s}\right)$, line impedance $\left(Z_{c}\right)$, line propagation constant $(\Gamma)$, and termination impedance $\left(Z_{t}\right)$. The source pressure $\left(P_{s}\right)$ is derived from $Z_{s}$.

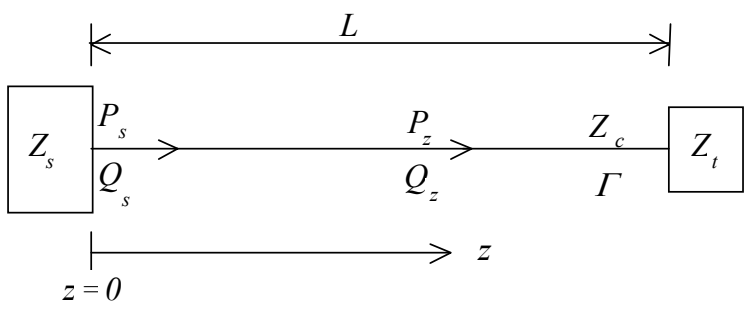

Fig. 4. Acoustic representation of a hydraulic circuit 
The pressure $\left(P_{z}\right)$ and volumetric flow velocity $\left(Q_{z}\right)$ at any harmonic frequency at a distance $z$ along the line are:

$$
\begin{gathered}
P_{z}=P_{i} e^{-\Gamma z}+P_{r} e^{\Gamma z} \\
Q_{z}=\frac{1}{Z_{c}}\left(P_{i} e^{-\Gamma z}-P_{r} e^{\Gamma z}\right)
\end{gathered}
$$

where $P_{i}$ and $P_{r}$ are the complex incident and reflected pressures, respectively.

The termination reflection coefficient, $C_{r}$, is defined by the ratio of the reflected pressure to the incident pressure:

$$
C_{r}=\frac{P_{r}}{P_{i}}
$$

The pressures at locations $z_{1}$ and $z_{2}$ are:

$$
\begin{aligned}
& P_{z 1}=P_{i} e^{-\Gamma z_{1}}+P_{r} e^{\Gamma z_{1}} \\
& P_{z 2}=P_{i} e^{-\Gamma z_{2}}+P_{r} e^{\Gamma z_{2}}
\end{aligned}
$$

Solving Equations (35) and (36) for $P_{i}$ and $P_{r}$, and substituting into Equation (34), the reflection coefficient is obtained:

$$
R=\frac{-\left(P_{z 1} e^{-\Gamma z_{2}}-P_{z 2} e^{-\Gamma z_{1}}\right)}{P_{z 1} e^{\Gamma z_{2}}-P_{z 2} e^{\Gamma z_{1}}}
$$

If the impedance of the termination is $Z_{t}$, applying Equations (32) and (33) at the boundary $z^{\prime}=0$ (i.e., $\left.z=L\right)$ gives:

$$
\begin{gathered}
\left(P_{i}+P_{r}\right)_{z^{\prime}=0}=\left(P_{t}\right)_{z^{\prime}=0} \\
{\left[\left(P_{i}-P_{r}\right) / Z_{c}\right]_{z^{\prime}=0}=\left(P_{t} / Z_{t}\right)_{z^{\prime}=0}}
\end{gathered}
$$

By rearranging the above two equations and combining with Equation (34), the termination impedance can be represented in terms of $Z_{c}$ and $C_{r}$ :

$$
Z_{t}=\left(\frac{1+C_{r}}{1-C_{r}}\right) Z_{c}
$$

$Z_{c}$ is the characteristic impedance in the tubing given by Chen and Hastings (1992):

$$
Z_{c}=\frac{\rho_{f} c}{\pi r_{i}^{2}}\left[1-\frac{2}{j r_{i} \sqrt{j \omega / v}} \frac{\mathrm{J}_{1}\left(j r_{i} \sqrt{j \omega / v}\right)}{\mathrm{J}_{0}\left(j r_{i} \sqrt{j \omega / v}\right)}\right]^{-1 / 2}
$$


where $c$ is the sound speed; $\omega$ is the angular frequency; $r_{i}$ is the inner radius of transmission line; $v$ is the density and kinematic viscosity of the fluid, respectively; and $\mathrm{J}_{0}$ and $\mathrm{J}_{1}$ denote the zero- and first-order Bessel functions of the first kind, respectively.

The measuring pressure signals before the valve, the termination impedance can be readily determined by Equation (37) and (40). Fig. 5 displays the estimated impedance of the rotary valve in power steering system at various opening positions. The data show that modeling this valve as a pure resistance is not appropriate as a strong reactive component of the impedance is apparent.
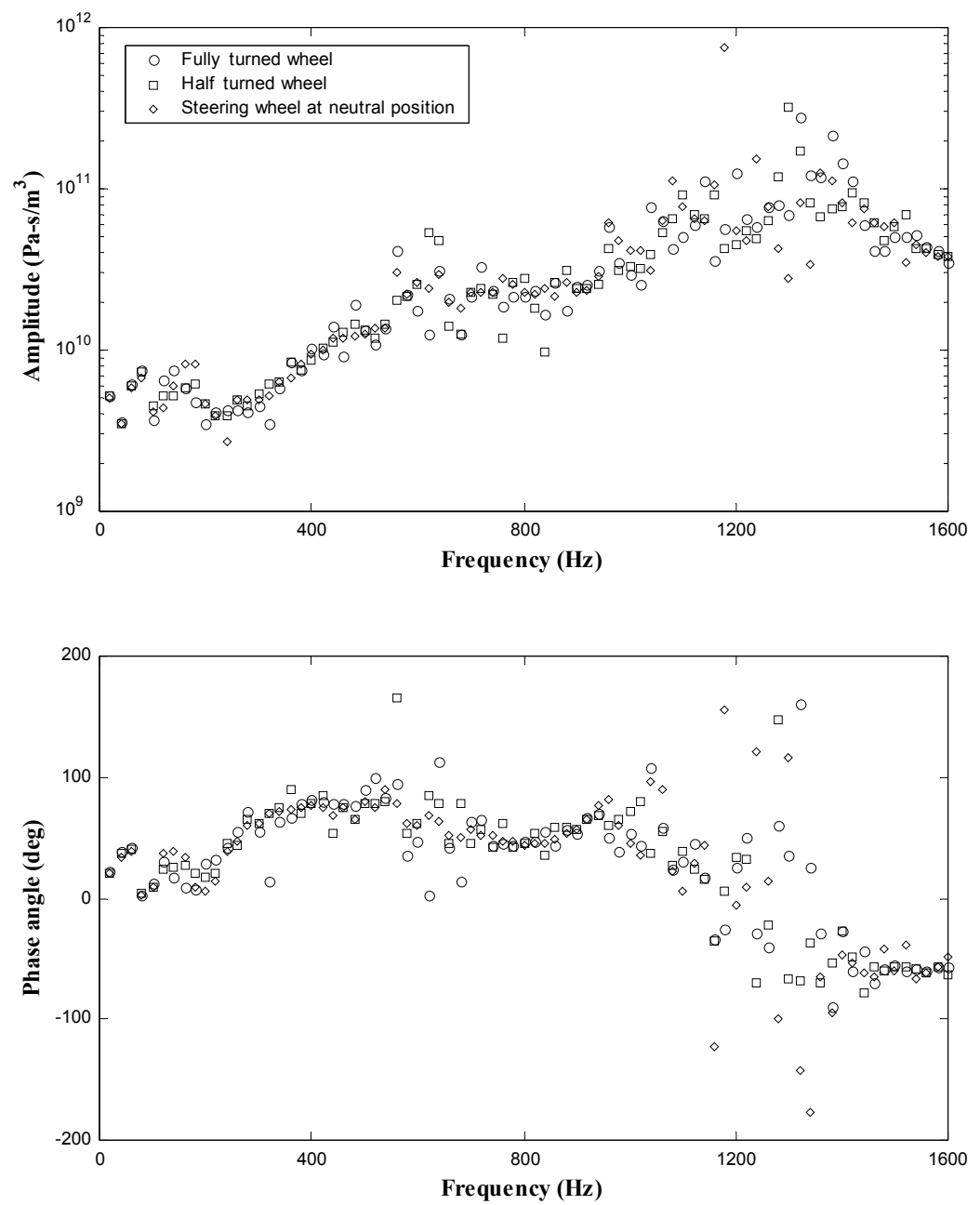

Fig. 5. Amplitude and phase angle of the valve impedance 


\section{Experimental results}

An automotive hydraulic power steering tubing system was tested in this research. Detailed layout of this three-dimensional tubing transmission line was provided by the manufacturer. Since this study addresses pump induced noise, a system with a pump source was set up to verify the transfer matrix model for the tubing system. Fig. 6 illustrates the system layout. This includes the power steering pump, hydraulic transmission lines, a rack and pinion unit, steering wheel and column, and rotary valve. The steering pump is driven by an electric motor through a belt. A variable speed, AC controller is used to control the electric motor and vary the speed of pump. In this setup, a water-cooling system using a coil heat exchanger is used. Water from the building supply circulates through the coil heat exchanger connected to the return line and then flows into a drain.

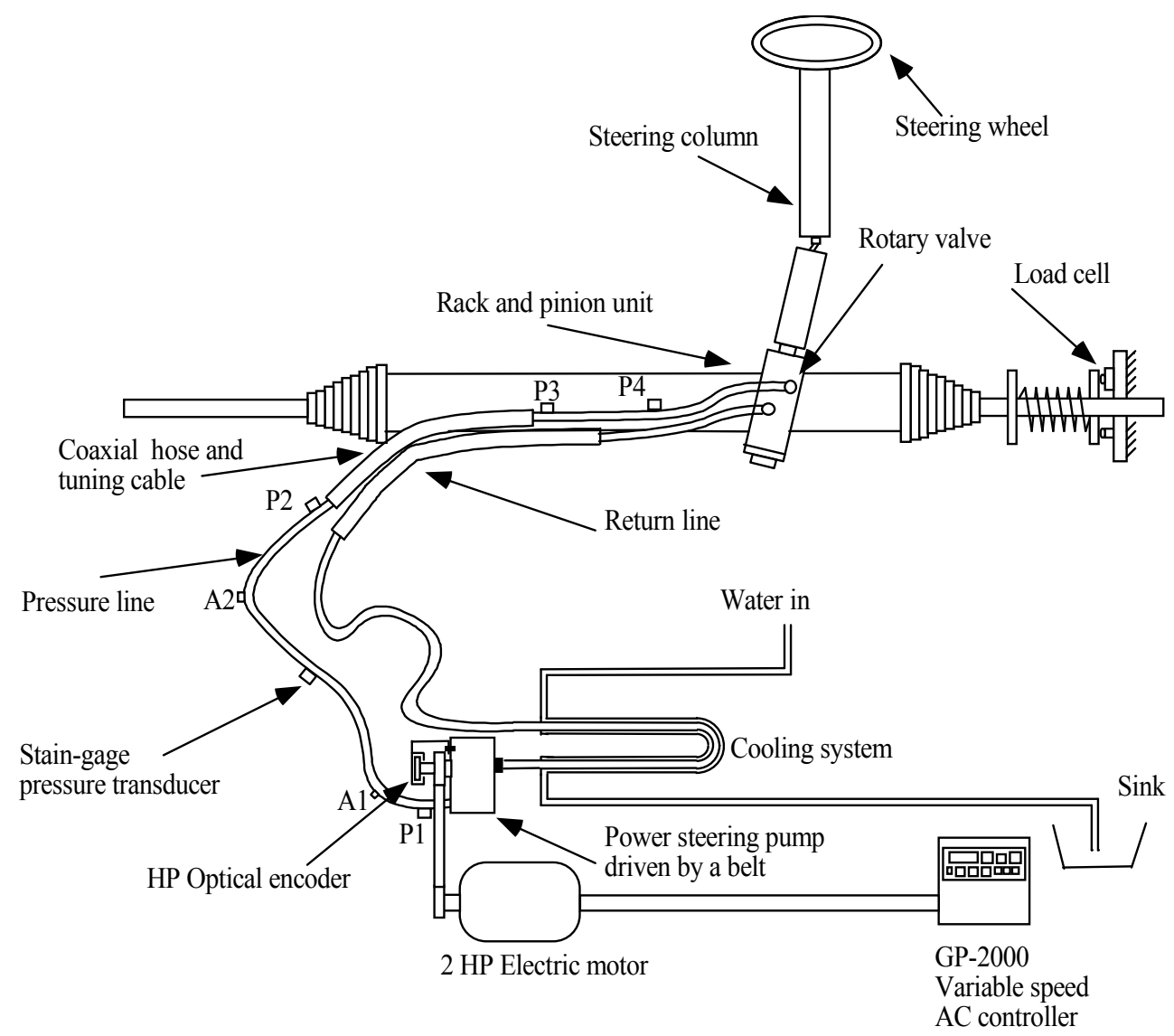

Fig. 6. Experimental setup for an automotive hydraulic power steering tubing system 
Four piezoelectric pressure transducers are used to measure the dynamic pressure in this system. The first pressure transducer (P1) is placed at the outlet of the pump to measure the source of pressure disturbance. The fourth one (P4) is located at the inlet of the rotary valve so that the amplitude ratio of outlet pressure to inlet pressure (P4/P1) can be measured and compared to the model prediction. The pressure signals are connected to the Kistler Charge amplifier and then to a HP3566A 8-channel analyzer. Data are saved in a computer and retrieved later for further analysis.

Because the focus of this study is to investigate the fluidborne noise propagation in the tubing system and interaction with the tubing structure, the pressure frequency response of the tubing transmission line is investigated. To correlate the transfer matrix model with better accuracy, the sound speed in steel tubing and damping factor are experimentally estimated (Chen, 2001). The sound speed was optimized to be $1374 \mathrm{~m} / \mathrm{s}$. The frequencydependent damping in the system was estimated based on the Half-Power method. Figs. 7 and 8 display the frequency response for the outlet pressure of the pressure side transmission line (P4) with different valve opening due to the steering wheel positions for an all steel tubing system. The model prediction and experimental data match very well. Good agreement was obtained.

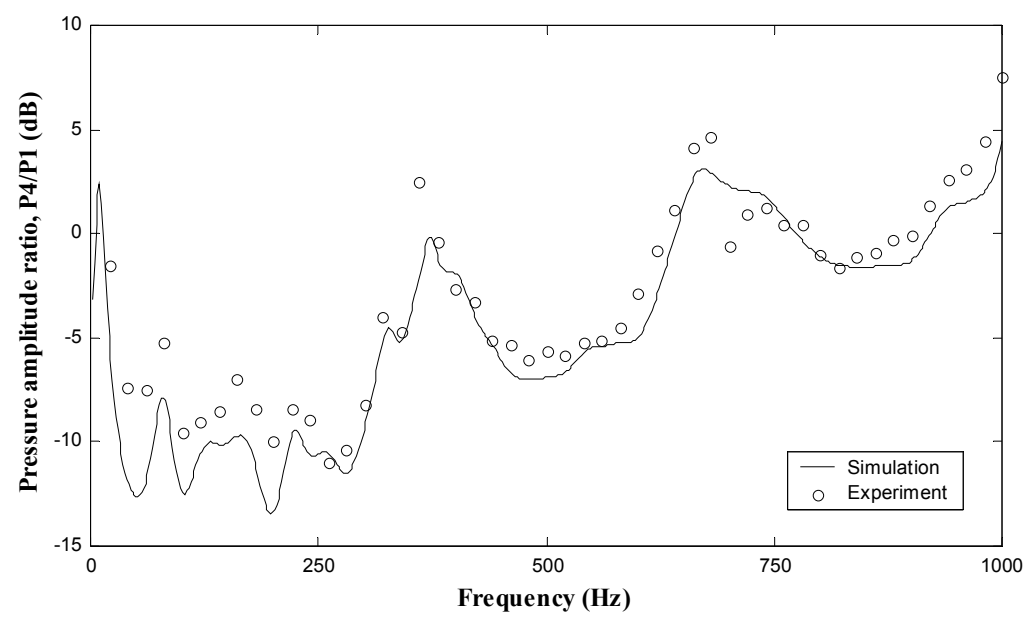

Fig. 7. Pressure response of an all steel tubing system with a fully turned steering wheel. 


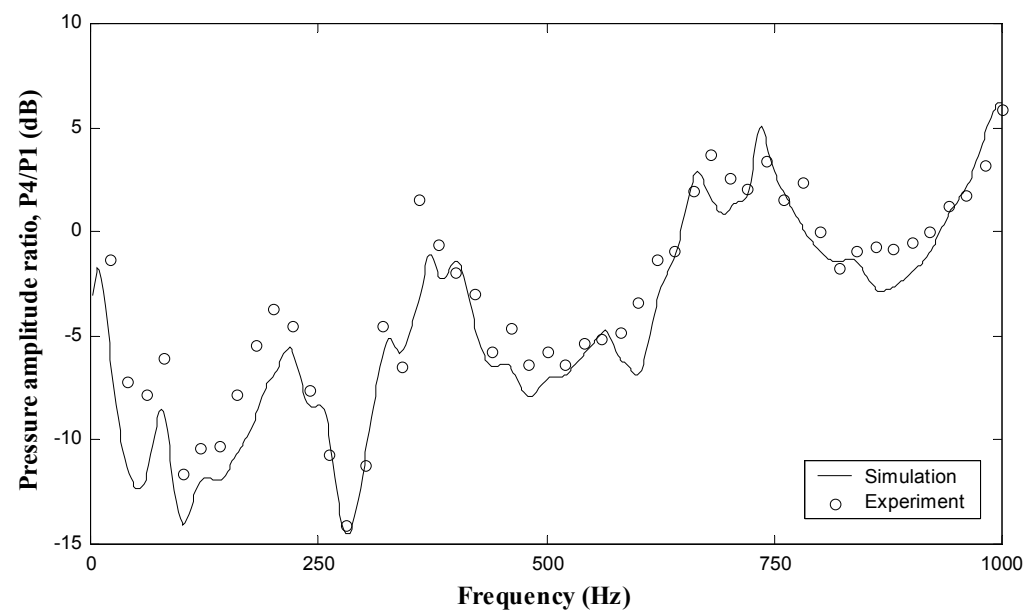

Fig. 8. Pressure response of an all steel tubing system with a steering wheel at neutral position

\section{Conclusions}

A distributed-parameter transfer-matrix model is developed to predict the fluidborne noise in a complex tubing system. This study provides a systematic approach to predict the pump-induced fluidborne noise by incorporating the experimentally determined acoustic characteristics of valve termination. The developed model was supported by experimental measurement with good agreements. Inclusion of Poisson and Bourdon effects in the model provide better predictions. Furthermore, the transfer matrix-partitioning algorithm presented here not only can reduce truncation error but also be more efficient in comparison with the matrix chain multiplication. It is also noted that the damping of the tubing system needs to be included to better predict the peak amplitude. The mathematical model presented can be applied to the analysis of noise in other hydraulic systems, such as those used in air conditioners and power plants. However, to fully characterize the noise propagation/transmission in the tubing system, SBN (not presented here, but can also be predicted by the developed model) should also be investigated because of fluid-structure interaction.

\section{References}

Brown F.T. \& Tentarelli S.C. (1988). Analysis of Noise and Vibration in Complex Tubing System with Fluid-Filled Interactions. 43rd National Conference on Fluid Power, 1988, pp. 139-149 
Bundy, D.D.; Wiggert, D.C. \& Hatfield F.J. (1991). The Influence of Structural Damping on Internal Pressure during a Transient Flow, ASME Journal of Fluid Engineers, Vol. 113, pp. 424-579

Chen C.-C. (1992). A Theoretical Analysis of Noise Reduction in Automotive Power Steering Transmission Lines. M.S. Thesis, 1992, The Ohio State University, Columbus, Ohio

Chen C.-C. \& Hastings M.C. (1992). Noise reduction in Power Steering Transmission Lines. Proceedings of the International Congress on Noise Control Engineering, 1992, Vol. 1, pp. $67-72$

Chen C.-C. \& Hastings M.C. (1994). Half-wavelength Tuning Cable for Passive Noise Control in Automotive Power Steering Systems. Active Control of Vibration and Noise (K. W. Wang et al., eds.), 1994, ASME DE-75, pp. 355-361

Chen C.-C. (2001). An Investigation of Noise and Vibration in an Automotive Power Steering System. Ph.D. Dissertation, 2001, The Ohio State University, Columbus, Ohio

Clark RA. Torsional Wave Propagation in Hollow Cylindrical Bars. Journal of Acoustical Society of America, 1956; 28 (6), pp. 1163-1165

Davidson L.C. \& Smith, J.E (1969). Liquid-Structure Coupling in Curved Pipes. The Shock and Vibration Bulletin, 1969, Vol. 40, No. 4, pp. 197-207

Davidson L.C. \& Samsury D.R. (1972). Liquid-Structure Coupling in Curved Pipes - II. The Shock and Vibration Bulletin, 1972, Vol. 43. No. 1, pp. 123-135

Everstine G.C. (1986). Dynamic Analysis of Fluid-Filled Piping Systems Using Finite Element Techniques. Journal of Pressure Vessel Technology, 1986, Vol. 10, pp. 5761

Hatfield F.J. \& Davidson L.C. (1983). Experimental Validation of the Component Synthesis Method for Prediction Vibration of Liquid-Filled Piping. The Shock and Vibration Bulletin, 1983, Vol. 53, No. 2, pp. 1-10

Hatfield, F.J. , Wiggert D.C. \& Otwell R.S. (1982). Fluid Structure Interaction in Piping by Component Synthesis. ASME Journal of Fluid Engineers, 1982, Vol. 104, pp. 318325

Nanayakkara S. \& Perreia, N.D. (1986). Wave Propagation and Attenuation in Piping Systems. Journal of Vibration, Acoustics, Stress, and Reliability in Design, 1986, Vol. 108, pp. 441-446

Reissner E., Clark R.A. \& Gilroy R.I. (1952). Stresses and Deformations of Torsional Shells of an Elliptical Cross Section with Applications to the Problems of Bending of Curved Tubes and the Bourdon Gage. Transaction of ASME, Journal of Applied Mechanics, 1952, pp.37-48

Tentarelli S.C. (1990). Propagation of Noise and Vibration in Complex Hydraulic Tubing System. Ph.D. Dissertation, 1990, Lehigh University, Bethlehem, Pennsylvania

To C.W.S. \& Kaladi V. (1985). Vibration of Piping Systems Containing a Moving Medium. Transaction of ASME, Journal of Pressure Vessel Technology, 1985. Vol. 107, pp. 344-349 
Vigness I. (1943). Elastic Properties of Curved Tubes. Transaction of ASME, 1943, Vol.65, pp.105-117 


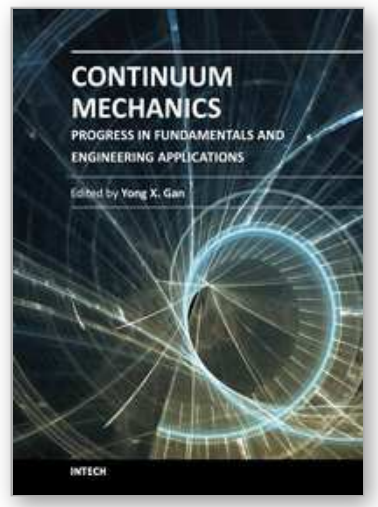

\author{
Continuum Mechanics - Progress in Fundamentals and \\ Engineering Applications \\ Edited by Dr. Yong Gan
}

ISBN 978-953-51-0447-6

Hard cover, 158 pages

Publisher InTech

Published online 28, March, 2012

Published in print edition March, 2012

Continuum Mechanics is the foundation for Applied Mechanics. There are numerous books on Continuum Mechanics with the main focus on the macroscale mechanical behavior of materials. Unlike classical Continuum Mechanics books, this book summarizes the advances of Continuum Mechanics in several defined areas. Emphasis is placed on the application aspect. The applications described in the book cover energy materials and systems (fuel cell materials and electrodes), materials removal, and mechanical response/deformation of structural components including plates, pipelines etc. Researchers from different fields should be benefited from reading the mechanics approached to real engineering problems.

\title{
How to reference
}

In order to correctly reference this scholarly work, feel free to copy and paste the following:

Chuan-Chiang Chen (2012). Noise and Vibration in Complex Hydraulic Tubing Systems, Continuum Mechanics - Progress in Fundamentals and Engineering Applications, Dr. Yong Gan (Ed.), ISBN: 978-953-510447-6, InTech, Available from: http://www.intechopen.com/books/continuum-mechanics-progress-infundamentals-and-engineering-applications/noise-and-vibration-in-hydraulic-piping-systems

\section{INTECH}

open science | open minds

\section{InTech Europe}

University Campus STeP Ri

Slavka Krautzeka 83/A

51000 Rijeka, Croatia

Phone: +385 (51) 770447

Fax: +385 (51) 686166

www.intechopen.com

\section{InTech China}

Unit 405, Office Block, Hotel Equatorial Shanghai

No.65, Yan An Road (West), Shanghai, 200040, China 中国上海市延安西路65号上海国际贵都大饭店办公楼 405 单元

Phone: +86-21-62489820

Fax: $+86-21-62489821$ 
(C) 2012 The Author(s). Licensee IntechOpen. This is an open access article distributed under the terms of the Creative Commons Attribution 3.0 License, which permits unrestricted use, distribution, and reproduction in any medium, provided the original work is properly cited. 